\title{
SCIENTIFIC REP

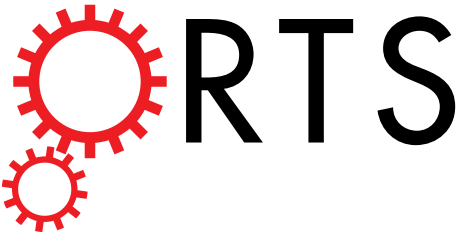 \\ OPEN \\ How to Regenerate and Protect Desert Riparian Populus euphratica Forest in Arid Areas
}

Received: 10 May 2015

Accepted: 25 September 2015

Published: 20 October 2015

\author{
Hongbo Ling ${ }^{1,2}$, Pei Zhang ${ }^{1,2}$, Hailiang $X u^{1} \&$ Xinfeng Zhao ${ }^{1}$
}

We found that the most suitable flooding disturbance model for regenerating Populus euphratica forest was two to three times per year with a duration of $15-20$ days and an intensity of $25-30 \mathrm{~m}^{3} / \mathrm{s}$. The flooding should take place during the seed emergence to young tree growth stages, and should be based on flooding experiments and data from vegetation quadrats and ecological water conveyance. Furthermore, we found that tree-ring width index for $P$. euphratica declined as the groundwater depth increased, and ascertained that the minimum groundwater depths for young trees, near-mature trees, mature trees and over-mature trees were $4.0 \mathrm{~m}, 5.0-5.4 \mathrm{~m}, 6.9 \mathrm{~m}$ and $7.8 \mathrm{~m}$, respectively. These were derived from a quantitative relationship model between groundwater depth and tree-ring width index. The range for ecological water conveyance volume was 311-320 million $\mathrm{m}^{3}$ in the lower reaches of the Tarim River. This study not only provides a technical basis for sustainable ecological water conveyance in the Tarim River Basin, but also offers a theoretical guide and scientific information that could be used in similar areas to regenerate and protect Populus euphratica around the world.

Populus euphratica is a rare, ancient and endangered species, and is only able to form forests in inland river basins located in arid areas ${ }^{1-4}$. It is also an essential component of desert riparian ecosystems $\mathrm{s}^{5,6}$. The Forest Tree Genetic Resources Panel of the Food and Agriculture Organization of the United Nations confirmed that $P$. euphratica was a core protected tree in arid and semi-arid areas ${ }^{7,8}$. P. euphratica is mainly found in mid and west China, north Africa and southern Europe ${ }^{9,10}$. China has the largest area of $P$. euphratica, which accounts for $61 \%$ of the global $P$. euphratica forest ${ }^{11}$. Specifically, the natural $P$. euphratica forest in the Tarim River Basin, Xinjiang, accounts for $54 \%$ of the global and $89 \%$ of China's P. euphratica area $^{8}$, and represents an essential tree genetic resource ${ }^{12,13}$. Desert riparian forest mainly contains $P$. euphratica and it forms a natural eco-barrier that protects the development of oases, stabilizes river channels, maintains the ecological balance of river basins, and helps form fertile forest soil ${ }^{6,14,15}$. However, since the $1950 \mathrm{~s}$, the use of the Tarim River water resource has become increasingly unsustainable due to climate change and intensive human disturbance ${ }^{16-19}$, and this has led to the loss of desert riparian forest in the lower reaches of Tarim River ${ }^{18-20}$. Therefore, how to regenerate and protect the damaged desert riparian ecosystem, a chief component of which is $P$. euphratica, has become a major concern of the Chinese government. In 2000, the Chinese government spent 10.7 billion yuan on the "Ecologic Water Conveyance Engineering" (EWCE) Project, whose aim was to reconstruct and protect the desert riparian P. euphratica forest in the lower reaches of the Tarim River.

The regeneration and protection of desert riparian P. euphratica forest is mainly based on river flooding disturbance and uplifting the groundwater table level ${ }^{15,21-25}$. There have been many previous studies on river flooding disturbance in arid lands, but most of the research has focused only on natural flooding disturbance effects on soil physics and chemical properties, distribution of plant communities, community structure, species diversity and the soil seed bank $^{26-29}$. In addition, because some indices of natural

${ }^{1}$ State Key Laboratory of Desert and Oasis Ecology, Xinjiang Institute of Ecology and Geography, Chinese Academy of Sciences (CAS), Urumqi 830011, China. ' ${ }^{2}$ niversity of Chinese Academy of Sciences, Beijing 100049, China. Correspondence and requests for materials should be addressed to H.X. (email: linghongboog29@163.com) 
flooding disturbance, such as intensity, frequency and duration, fluctuate and are volatile, simulation experiments cannot be conducted in the area ${ }^{26,30-32}$. Hence, previous studies have been unable to identify a suitable river flooding disturbance management plan that will help regenerate damaged ecosystems using artificial regulation (e.g., the EWCE Project in the lower reaches of the Tarim River).

Many studies ${ }^{33-36}$ have indicated that the relationship is close to streamflow and tree-ring data. Streamflow is mainly converted into groundwater to meet the ecological water requirement of vegetation $^{37,38}$. Similarly, the water required by the desert riparian $P$. euphratica forest is mainly supplied by groundwater ${ }^{37}$. Previous research determined the minimum groundwater depth that will promote $P$. euphratica growth for the whole forest in terms of plant eco-physiological variables and the tree-ring radial stem growth of $P$. euphratica etc ${ }^{8,39,40}$. However, diameter at breast height (DBH) for $P$. euphratica trees is correlated with the different root distributions corresponding to different groundwater depths. Therefore, based on the results of previous studies, the EWCE Project is unable to divide water according to the different DBHs of trees using the present recommendations $s^{8,39,40}$. In addition, some studies ${ }^{39,41}$ could not accurately describe the variation in $P$. euphratica growth due to the different groundwater depths because radial stem growth is affected by a self-growth trend. Consequently, the response models based on de-growth-trend tree-ring width indices for $P$. euphratica tree-ring growth and groundwater depth are rare. According to the above analysis, this study used the ecological water conveyance data from 2000-2012 and the groundwater depth data acquired from 30 monitoring wells, to analyze the effects of different flooding disturbances on P. euphratica seedling growth. Firstly, we produced an optimal disturbance model for seedling growth, based on flood disturbance experiments conducted in the lower reaches of the Tarim River. Secondly, a quantitative relationship model was constructed using different groundwater depths and tree-ring width indices, and then we determined the minimum groundwater depths for different tree DBHs and developed an effective ecological water conveyance management plan to regenerate and protect desert riparian P. euphratica forest in the lower reaches of the Tarim River. The aims of this study were (1) to provide technical assistance that will help achieve sustainable ecological water conveyance in the Tarim River Basin, and (2) to offer scientific guidance that can be used in similar areas to regenerate and protect $P$. euphratica forest around the world.

\section{Materials and Methods}

Regional setting. The Tarim River Basin $\left(34.20^{\circ} \sim 43.39^{\circ} \mathrm{N}, 71.39^{\circ} \sim 93.45^{\circ} \mathrm{E}\right)$ is located in south Xinjiang, China, and abuts the Taklamakan Desert ${ }^{16}$. The Tarim River is the longest inland river in China, and is surrounded by the Aksu, Yarkant, Kaxgar, Hetian, Keriya, Weigan, Kuqa, Dina, KaiduKongque and Qarqan rivers ${ }^{16}$. The basin wide runoffs are mainly supplied by ice-melt water and precipitation, which amount to 39.83 billion $\mathrm{m}^{3}$ per year. The total basin area is 1.02 million $\mathrm{km}^{2}$, and covers five prefectures, forty-two counties and fifty-five regiments of the Construction and Production Corps of Xinjiang ${ }^{20}$. The population is 11.03 million.

The main part of the Tarim River is a closed watershed and has a total length of $1321 \mathrm{~km}^{37}$. In the past, there were nine great rivers flowing into the Tarim River. However, since the 1940 s, the Kaxgar, Weigan, Keriya, Kuqa, Dina, Kaidu-Kongque and Qarqan rivers have been cut off from the Tarim River because of climate change and human activities ${ }^{20}$. Only the Hetian, Yarkant, Kongque and Aksu rivers remain tributaries of the Tarim River $^{37}$.

Both sides of the Tarim River contain desert riparian forest, mainly P. euphratica, which is one of the most important arid area forest vegetation communities in Asia $^{8}$. Shrub vegetation mainly consists of Halostachys caspica, Tamarix and Haloxylon ammodendron, and the main herbs are Phragmites australis, Alhagi sparsifolia and Karelinia caspica ${ }^{37}$.

Our research area was located in the lower reaches of the Tarim River, downstream of the Daxihaizi cross-section. It covered a total area of $2191 \mathrm{~km}^{2}$ (Fig. 1). This area is one of the most arid areas in China with a mean annual precipitation of $40 \mathrm{~mm}$ and mean annual potential evaporation of $2590 \mathrm{~mm}^{42}$. The cumulative temperature above $10^{\circ} \mathrm{C}$ for this area is 4040 to $4300^{\circ} \mathrm{C}$, with a mean diurnal range of $13^{\circ} \mathrm{C}$ to $17^{\circ} \mathrm{C}^{38}$.

The lower reaches of Tarim River have experienced water cut offs since 1972, which has led to a reduction in the area of the desert riparian forest, a loss of $P$. euphratica forest and environmental degeneration $^{37,38}$. In order to rescue the eco-environment of the lower reaches of the Tarim River, and to regenerate and protect desert riparian forest, the Chinese government, since 2000, has implemented the EWCE Project, which stretches from the Kongque River to the downstream Tarim River area ${ }^{24,37,38}$. From 2000 to 2006, eight times the normal water conveyance has flowed into Taitema Lake, which amounts to a total of 2.25 billion $\mathrm{m}^{3}$ and a mean annual amount of 0.32 billion $\mathrm{m}^{3}$ (Fig. 2). Between 2007 and 2009, twice the usual amount of water was allowed to flow, but because this was far short of the required amount (total amount, 20 million $\mathrm{m}^{3}$; mean annual amount, 10 million $\mathrm{m}^{3}$ ), the water head only reached the Kardayi Section. However from 2010 to 2012, three times the usual amount of water, which supplied 1.91 billion $\mathrm{m}^{3}$, at a mean annual amount of 0.64 billion $\mathrm{m}^{3}$, meant that water was able to resupply Taitema Lake again. As the EWCE Project proceeds, river flooding will expand to cover both sides of the river channel, which will lead to a rise in the groundwater table and help repair the damaged desert riparian forest ${ }^{37-39}$.

Data Resources. The hydrological data used in this research were taken from the EWCE Project and the groundwater depths (the elevation minus groundwater table level) data acquired from 30 monitoring 


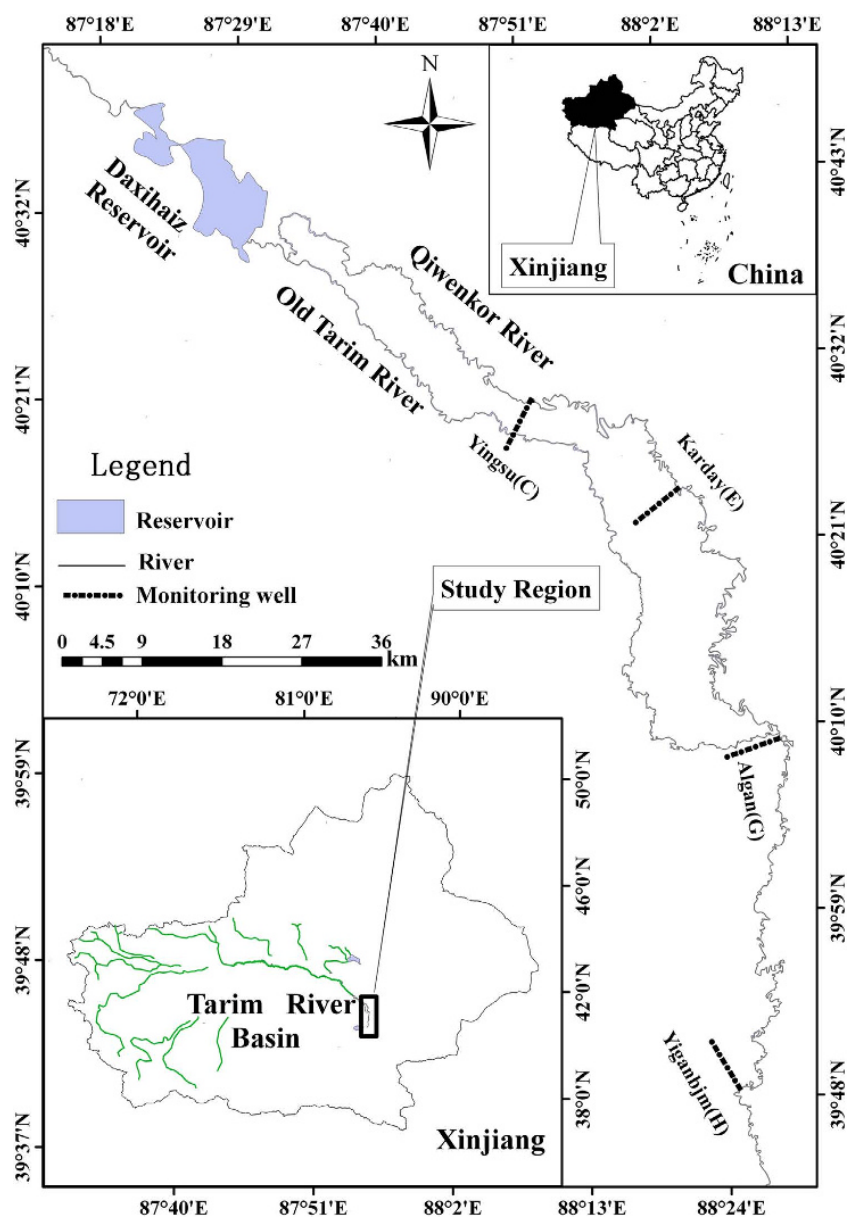

Figure 1. Distribution map of the four selected transects and the water conveyance channel in the lower Tarim River, China (The map was created by Hongbo ling based on the software ArcMap).

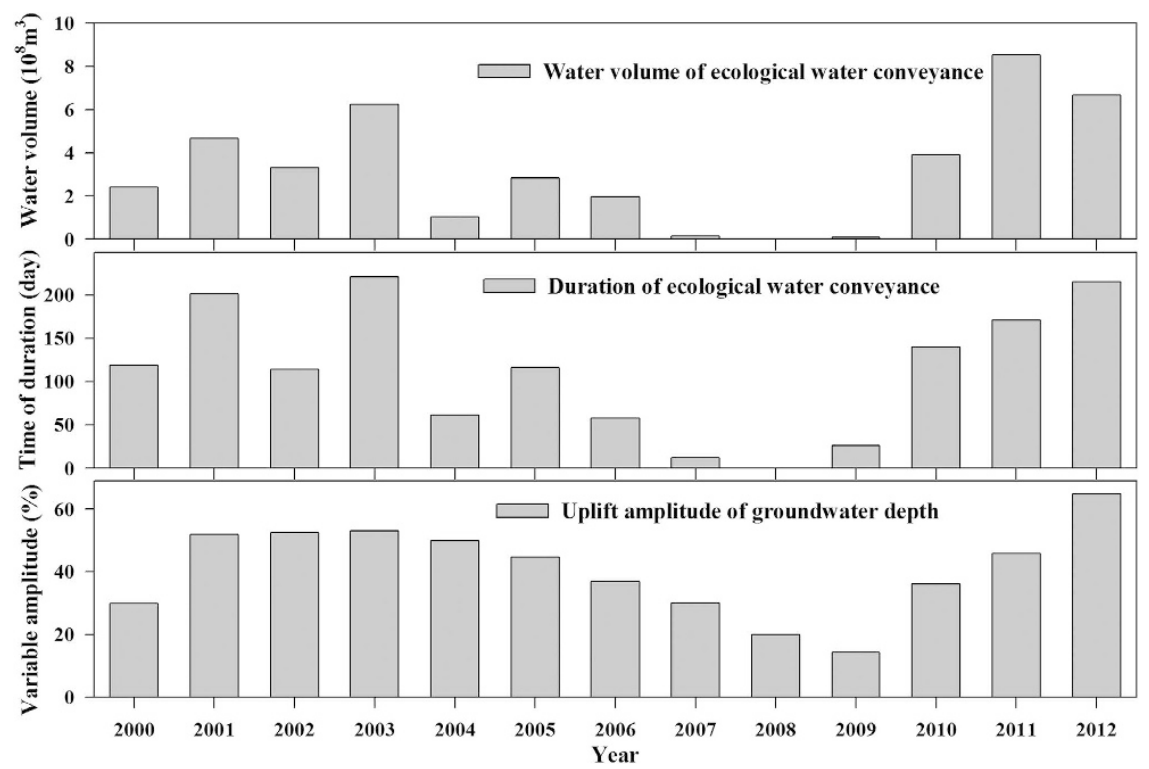

Figure 2. Water volume, duration and groundwater table uplifts due to increases in ecological water conveyance. 


\begin{tabular}{|c|c|c|c|c|}
\hline Number & Specie & Genera & Family & Age \\
\hline 1 & Populus euphratica Oliv. & Populus L. & Salicaceae & $1-3 a$ \\
\hline 2 & Tamarix ramosissima Ledeb. & Tamarix L. & Tamaricaceae & $1-3 a$ \\
\hline 3 & Tamarix hispida Willd. & Tamarix L. & Tamaricaceae & $1-3 a$ \\
\hline 4 & Tamarix hohenacheri Bunge. & Tamarix L. & Tamaricaceae & $1-3 a$ \\
\hline 5 & Tamarix elongata Ledeb. & Tamarix L. & Tamaricaceae & $1-3 a$ \\
\hline 6 & Tamarix laxa Willd. & Tamarix L. & Tamaricaceae & $1-3 a$ \\
\hline 7 & Alhagi sparsifolia Shap. & Alhagi Gagneb. & Fabaceae & $1-2 \mathrm{a}$ \\
\hline 8 & Halimodedron halodendron Voss & $\begin{array}{l}\text { Halimodendron } \\
\text { Fisch. ex DC. }\end{array}$ & Fabaceae & $1-2 a$ \\
\hline 9 & Glycurrhiza inflata Bat. & Glycyrrhiza L. & Fabaceae & $1-2 a$ \\
\hline 10 & Sophora alopecuroides L. & Sophora L. & Fabaceae & $1-2 \mathrm{a}$ \\
\hline 11 & Halostachys caspica C. A. Mey. & $\begin{array}{l}\text { Halostachys C. A. } \\
\text { Mey. }\end{array}$ & Chenopodiaceae & $1-2 \mathrm{a}$ \\
\hline 12 & Halocnemum strobiaceum Bieb. & Halocnemum Bieb. & Chenopodiaceae & $1-2 \mathrm{a}$ \\
\hline 13 & Salsola pellucida Litv. & Salsola L. & Chenopodiaceae & la \\
\hline 14 & Salsola ruthenica Iljin. & Salsola L. & Chenopodiaceae & la \\
\hline 15 & Halogeton glomeratus C. A. Mey. & Salsola L. & Chenopodiaceae & 1a \\
\hline 16 & Suaeda prostrata Pall. & $\begin{array}{l}\text { Suaeda Forsk. Ex } \\
\text { Scop. }\end{array}$ & Compositae & $1-2 \mathrm{a}$ \\
\hline 17 & Halogeton arachnoideus Moq. & Saliconia L. & Compositae & $1 \mathrm{a}$ \\
\hline 18 & Karelinia caspica Less. & Karelinia Less. & Compositae & $1-2 a$ \\
\hline 19 & $\begin{array}{l}\text { Yang Hexinia polydichotoma } \mathrm{H} \text {. } \\
\text { L. Yang. }\end{array}$ & Hexinia H. L. Yang & Compositae & $1-2 \mathrm{a}$ \\
\hline 20 & Inula salsoloides Ostenf. & Inula L. & Compositae & $1-2 \mathrm{a}$ \\
\hline 21 & Taraxacum sp. & Taraxacum Weber & Compositae & $1-2 \mathrm{a}$ \\
\hline 22 & Acroption repens Prodr. & Acroptilon Cass. & Compositae & $1-2 a$ \\
\hline 23 & Scirpus planiculmis Fr. Schmidt & Scirpus L. & Cyperaceae & $1-2 \mathrm{a}$ \\
\hline 24 & $\begin{array}{l}\text { Scirpus tabernaemontani C. C. } \\
\text { Gmel. }\end{array}$ & Scirpus L. & Cyperaceae & $1-2 \mathrm{a}$ \\
\hline 25 & Aeluropus pungens Var. & Aeluropus Trin & Gramineae & $1-2 \mathrm{a}$ \\
\hline 26 & Phragmites australis Trin. & Phragmites Trin & Gramineae & $1-2 \mathrm{a}$ \\
\hline 27 & Apocynum venetum $\mathrm{L}$. & Apocynum L. & Apocynaceae & $1-2 \mathrm{a}$ \\
\hline 28 & Lycium ruthenicum Murr. & Lycium L. & Solanaceae & $1-2 a$ \\
\hline 29 & Elaeagnus angustifolia Linn. & Elaeagnus & Elaeagnaceae & $1-3 a$ \\
\hline 30 & Equisetum arvense L. Sp. pl & Hippochaete Milde & Equisetaceae & $1-2 \mathrm{a}$ \\
\hline 31 & Cynanchum sibiricum Willd. & Cynanchum L. & Asclepiadaceae & $1-2 \mathrm{a}$ \\
\hline
\end{tabular}

Table 1. Vegetative investigation of the quadrats for flooding experiment in the lower reaches of Tarim River.

wells that were perpendicular to the river channel (the distances from wells to the river channel were $50 \mathrm{~m}, 150 \mathrm{~m}, 300 \mathrm{~m}, 500 \mathrm{~m}, 750 \mathrm{~m}$ and $1050 \mathrm{~m}$ ) from $2000-2012$. The vegetation data were taken from 50 flood experimental areas, 467 vegetation quadrats (Table 1) and 434 tree-ring cores from P. euphratica trees with different DBHs that were located in the lower reaches of the Tarim River.

Flooding experiment. Based on the ecological water conveyance data acquired, combined with the actual river flooding conditions recorded by field investigations in the study area, we divided the flooding factors (frequency, duration and intensity) into four grades in the downstream reaches of the Tarim River (Table 2).

According to the grades, we randomly placed 3-5 vegetative quadrats that were $1 \mathrm{~m} \times 1 \mathrm{~m}, 2 \mathrm{~m} \times 2 \mathrm{~m}$ or $5 \mathrm{~m} \times 5 \mathrm{~m}$ in size, to investigate the composition, number, height, $\mathrm{DBH}$, crown width, coverage and frequency of vegetation so that we could measure changes in plant community structure under different flooding disturbance regimes. This amounted to 50 sample plots and 467 quadrats in the study area.

The results from the field research enabled us to calculate the important values (IV) for P. euphratica seedlings in each quadrat so that we could determine whether the $P$. euphratica seedlings would survive or not. 


\begin{tabular}{|l|l|c|c|}
\hline Grade & Flooding frequency & $\begin{array}{c}\text { Flooding } \\
\text { duration }(\mathbf{d a y})\end{array}$ & $\begin{array}{c}\text { Flooding } \\
\text { intensity }\left(\mathbf{m}^{3} / \mathbf{s}\right)\end{array}$ \\
\hline 1 & once in one or two years & $5-10$ & $20-25$ \\
\hline 2 & once or twice per year & $10-15$ & $25-30$ \\
\hline 3 & $2-3$ times per year & $15-20$ & $30-35$ \\
\hline 4 & $4-5$ times per year & $>20$ & $35-40$ \\
\hline
\end{tabular}

Table 2. Gradient divisions for three flooding factors at monitoring sections in the Lower Tarim River.

\begin{tabular}{|l|l|c|l|}
\hline DBH $(\mathbf{c m})$ & Growth stage & Age(year) & Growth characteristics \\
\hline $4-10$ & Young trees & $5-15$ & $\begin{array}{l}\text { Branches grow broad leaves in the upper canopy, and narrow leaves in the lower } \\
\text { canopy. The trees have no characteristics of blossom and fruit setting. }\end{array}$ \\
\hline $10-30$ & Near-mature trees & $15-40$ & $\begin{array}{l}\text { Braches grow broad leaves in the canopy.A small amount of new braches are } \\
\text { germinated in the tree trunk. The trees begin to bloom and bear fruit. }\end{array}$ \\
\hline $30-40$ & Mature trees & $40-60$ & $\begin{array}{l}\text { Braches grow broad leaves in the canopy. No or few branches wither up. The trees are } \\
\text { at the peak period of blossom and fruit setting. }\end{array}$ \\
\hline$>40$ & Over-mature trees & $>60$ & $\begin{array}{l}\text { Braches grow broad leaves in the canopy.A large number of branches wither up.The } \\
\text { trees bear little or no fruit. }\end{array}$ \\
\hline
\end{tabular}

Table 3. Classification standards of five grades for Populus euphratica in the lower Tarim River.

$$
I V=(D r+C r+H r) / 3
$$

where $\mathrm{Dr}$ represents relative density; $\mathrm{Cr}$ represents relative coverage; and $\mathrm{Hr}$. represents relative height ${ }^{43,44}$.

Sampling and processing of tree rings. Four transects where $P$. euphratica predominated were selected as the study region, i.e., Yingsu (C), Karday (E), Algan (G) and Yiganbujima (I) (Fig. 1). We chose six to ten trees with different DBHs around one monitoring well in order to reduce the deviation. According to the principles of the International Tree-ring Database, we selected 217 trees and 434 tree-ring cores between August, 2009 and August, 2013., Based on the field survey and tree-ring analysis of $P$. euphratica forest in the lower reaches of Tarim River, the 217 trees were divided into five grades according to DBHs so that we could study the different $P$. euphratica growth periods. These were $4-10 \mathrm{~cm}$ (young trees), $10-30 \mathrm{~cm}$ (near-mature trees), $30-40 \mathrm{~cm}$ (mature trees) and $>40 \mathrm{~cm}$ (over-mature trees) (Table 3 ). The tree-ring sampling and cross-dating were completed according to the standards published by Fritts ${ }^{45}$. Two cores were taken from each tree using an increment borer.

The samples were handled according to dendro-chronological laboratory procedure (i.e., drying, mounting, sanding and primary cross-dating ${ }^{45,46}$. Firstly, the ring increments of $P$. euphratica were measured using the LINTAB ${ }^{\mathrm{TM} 6}$ system (precision of $0.001 \mathrm{~mm}$; Rinntech, Heidelberg, Germany). Secondly, cross-dating of increment series data was determined using COFECHA software ${ }^{47}$. Finally, to establish standard and residual chronologies, the growth trend curve for the raw ring increments of $P$. euphratica was fitted using the negative exponential formula in the ARSTAN software ${ }^{45,48}$.

Calculation of the tree-ring width index. In extreme arid lands (e.g., Tarim River Basin), groundwater and tree age are the two most critical factors influencing the tree-ring width of $P$. euphratica. In order to highlight the effect of groundwater on radial stem growth, we needed to remove the influence of tree age. Therefore, a standardized protocol for radial stem growth data was adopted, i.e., the raw ring growth value $\left(w_{i}\right)$, measured using COFECHA software, was divided by the expected value $\left(y_{i}\right)$ calculated from the growth trend curve by the negative exponential formula in the ARSTAN software. This produced a new sequence for the tree-ring width index $\left(I_{i}\right)$, as shown in formula $2^{49}$.

$$
I_{i}=\frac{w_{i}}{y_{i}}
$$

Monotony trend test and abrupt change test for tree-ring width index. The trend change for the tree-ring width index was analyzed using the Mann-Kendall monotony trend test. In the test process $^{39,50}$, when the statistic (i.e., $Z_{c}$ ) is positive, it reflects an upward trend; whereas when $Z_{c}$ is negative, it reflects a downward trend. If the checking standards are salient $\left(\left|Z_{c}\right| \geq\left|Z_{0.05}\right|=1.96\right.$ at the 95\% level; $\left|Z_{\mathrm{c}}\right| \geq\left|Z_{0.01}\right|=2.58$ at the $99 \%$ level), then the trend is credible, otherwise it is not. 

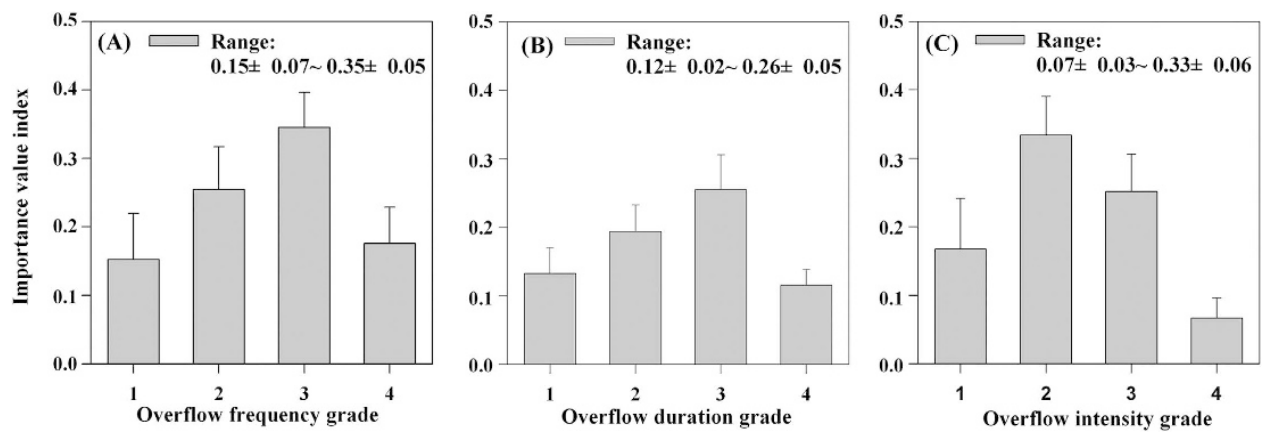

Figure 3. The importance values (IV) for Populus euphratica seedlings under different disturbance patterns.

To analyze abrupt change, we first calculated the turning point of the tree-ring width index and groundwater depth using the accumulated anomaly value ${ }^{41}$. Then we checked whether the abrupt changes in the tree-ring width indices either sides of the turning point were salient according to the Mann-Whitney abrupt change test ${ }^{39,51}$. If the statistic $\left(\left|Z_{c}\right|\right)>1.96$, then the abrupt change is significant, otherwise it is not.

\section{Results}

The most suitable river flooding disturbance model for $P$. euphratica seedlings $(\mathrm{DBH}<4 \mathrm{~cm})$. The importance value $(I V)$ can show the most suitable habitat for this species ${ }^{52}$. Based on the field trial results, we divided the 467 quadrats into different grades according to the disturbance patterns, calculated the $I V$ value for P. euphratica seedlings (Fig. 3) and identified the most suitable flooding disturbance model for $P$. euphratica seedling regeneration.

According to Fig. $3 \mathrm{~A}$, as the frequency of flooding disturbance increases, the $I V$ value shows a para-curve trend with the highest value appearing in Grade 3 (two to three times per year). When the overflow duration (Fig. 3B) is $<15-20$ days (i.e., Grade 3), then the $I V$ value is relatively high and Grade 3 is the highest, but over 20 days, the value drops significantly $(P<0.001)$. Figure $3 \mathrm{C}$ shows that Grade $2\left(25-30 \mathrm{~m}^{3} / \mathrm{s}\right)$ has the highest value and that the value declines significantly when the flood intensity is over $40 \mathrm{~m}^{3} / \mathrm{s}(P<0.001)$. Therefore, the most suitable flooding disturbance model is two to three times per year with a duration of $15-20$ days and an intensity of $25-30 \mathrm{~m}^{3} / \mathrm{s}$.

The effect of groundwater depth on young $P$. euphratica trees (DBHs $4-10 \mathrm{~cm}$ ). Flooding disturbance (or overflow) is the key factor affecting $P$. euphratica seedling survival ${ }^{53,54}$. A suitable groundwater depth is another essential environmental factor that ensures that seedlings can grow into young trees $^{55}$. However, trees with different DBHs respond to groundwater depth differently. Therefore, we divided the trees into five growth groups (i.e., seedling, young trees, near-mature trees, mature trees and over-mature trees) according to their DBHs. Based on the tree-ring width and groundwater depth data, we constructed a quantitative model that included tree-ring width index and groundwater depth and determined how tree-ring width index responded to groundwater depth (Fig. 4).

Figure $4(1 \mathrm{~A})$ shows that the tree-ring width index for young trees declines as the groundwater depth increases $\left(R^{2}=0.62, P<0.0001\right)$, which means that we can use the tree-ring index to deduce the most suitable groundwater depth. In addition, according to the Mann-Kendall monotony trend test (Table S1), when groundwater depth is between 0.6 to $8.8 \mathrm{~m}$, the test statistics for tree-ring width index decrease significantly ( $\mathrm{Zc}$ is $\left.-13.32,\left|Z_{\mathrm{c}}\right|>\left|Z_{0.01}\right|=2.58\right)$. This shows that $P$. euphratica growth is very sensitive to variation in groundwater depth. We can also calculate the decrease in tree growth for every $0.1 \mathrm{~m}$ increase in groundwater depth. Figure $4(1 \mathrm{~B})$ shows that the $4.0 \mathrm{~m}$ depth mark divides the curve into two parts: a left part (groundwater depth between 0.6 and $4.0 \mathrm{~m}$ ) and a right part (groundwater depth between 4.1 and $8.8 \mathrm{~m}$ ). When the groundwater depth is between 0.6 and $4.0 \mathrm{~m}$, the average tree-ring width index is higher than the total average, which indicates a sharp decrease. When the groundwater depth is between 4.1 and $8.8 \mathrm{~m}$, the average is lower than the total average, which means the tree-ring width index decreases slowly. According to the Mann-Whitney abrupt change test (Table S1), between the two groundwater depth intervals $(0.6-4.0 \mathrm{~m}$ and $4.1-8.8 \mathrm{~m})$, the mean value for tree-ring width index drops from 0.049 to 0.013 , and its abrupt change is significant at the 0.01 test level. $(\mathrm{Zc}=-7.75$, $\left.\left|Z_{c}\right|>\left|Z_{0.01}\right|=2.58\right)$. When the groundwater depth is $<4 \mathrm{~m}$, the decrease in $P$. euphratica radial stem growth is relatively small and the tree-ring width index response to groundwater depth becomes less sensitive, which means that $P$. euphratica growth is under stress. Thus, the minimum groundwater depth for young trees should be $<4.0 \mathrm{~m}$. 

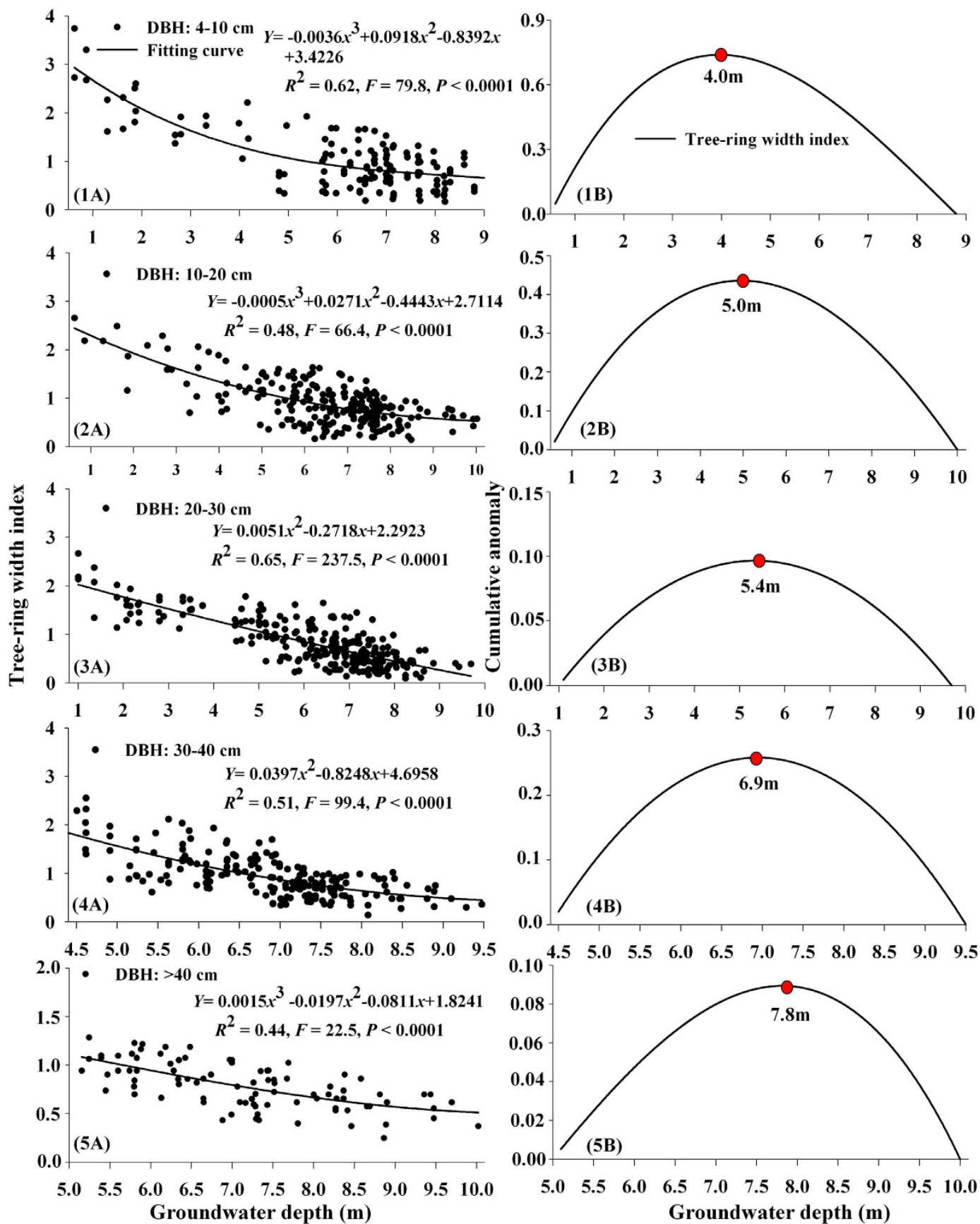

Figure 4. The relationships between the tree-ring width indexes for five grade DBHs and the groundwater depths (1A-5A), and the most suitable groundwater depths for P. euphratica (1B-5B).

The effect of groundwater depth on near-mature $P$. euphratica trees (DBHs of $10-30 \mathrm{~cm}$ ). $P$. euphratica trees with DBHs of $10-30 \mathrm{~cm}$ grew well, with lots of newly bursting branches, and could be described as near-mature trees. In order to efficiently identify the water resource need to protect these near-mature trees, we divided the trees into two grades according to $\mathrm{DBH}(10-20 \mathrm{~cm}$ and $20-30 \mathrm{~cm})$.

Figure $4(2 \mathrm{~A})$ shows that the tree-ring width index for young trees declines as the groundwater depth increases and this is significantly negatively correlated $(P<0.01)$. According to the Mann-Kendall monotony trend test (Table S2), the tree-ring width index declines significantly at the 0.01 test level $\left(\mathrm{Zc}=-14.35,\left|Z_{c}\right|>\left|Z_{0.01}\right|=2.58\right)$. Figure $4(2 \mathrm{~B})$ shows that the turning point for the decreasing tree-ring width index is $5.0 \mathrm{~m}$. In addition, the Mann-Whitney abrupt change test results (Table S2) for the two groundwater depth intervals $(0.6-5.0 \mathrm{~m}$ and $5.1-8.8 \mathrm{~m})$ show that the mean value for tree-ring width index drops significantly (test statistic $(\mathrm{Zc})$ is -8.39 ) from 0.031 to 0.013 . When the groundwater depth is $>5.0 \mathrm{~m}$, the tree-ring width index (trees with DBHs 10-20 cm) response to groundwater depth 
becomes less sensitive. Therefore, the most suitable groundwater depth for near-mature trees (with DBHs $10-20 \mathrm{~cm}$ ) should be $<5.0 \mathrm{~m}$.

Subsequently, we constructed a response function for tree-ring width index against the variation in groundwater depth based on the data for near-mature tree-rings (trees with DBHs $20-30 \mathrm{~cm}$ ) and groundwater depth (Figs $4(3 \mathrm{~A}, 3 \mathrm{~B})$ ).

Figure $4(3 \mathrm{~A})$ shows that there is a significant negative correlation between tree-ring width index for near-mature trees (DBHs $20-30 \mathrm{~cm})$ and groundwater depth $\left(R^{2}=0.62, P<0.0001\right)$. According to the Mann-Kendall monotony trend test (Table S3), increasing groundwater depth leads to a significant decrease in tree-ring width index $\left(Z c=-13.71,\left|Z_{c}\right|>\left|Z_{0.01}\right|=2.58\right)$. Figure 4(3B) and Table S3 show that the turning point is $5.4 \mathrm{~m}$, and between the two groundwater depth intervals $(1.1-5.4 \mathrm{~m}$ and $5.5-9.7 \mathrm{~m})$, the mean tree-ring width index value significantly drops $\left(\left|Z_{c}\right|=8.03>\left|Z_{0.01}\right|=2.58\right)$ at the 0.01 test level from 0.024 to 0.019 . Therefore, we can conclude that the minimum groundwater depth for near-mature trees $(\mathrm{DBHs} 20-30 \mathrm{~cm}$ ) is $5.4 \mathrm{~m}$. In brief, the sensitive interval for near-mature tree $(\mathrm{DBHs} 10-30 \mathrm{~cm}$ ) response to groundwater depth is between 5.0 to $5.4 \mathrm{~m}$, and the most suitable groundwater depth is $<5.4 \mathrm{~m}$.

The effect of groundwater depth on $P$. euphratica mature trees (DBHs $30-40 \mathrm{~cm}$ ). Mature $P$. euphratica trees are very important components of the P. euphratica community in the Tarim River Basin. Therefore, we studied the growth response of mature trees to different groundwater depths (Fig. 4(4A,4B) and Table S4).

According to Fig. 4(4A), there is a negative correlation between tree-ring width index for mature trees and groundwater depth $\left(R^{2}=0.51, P<0.0001\right)$. The Mann-Kendall monotony trend test (Table S4) shows that the tree-ring width index holds a significant decrease trend $\left(Z_{c}=-10.35>\left|Z_{0.01}\right|=2.58\right)$. Figure $4(4 \mathrm{~B})$ shows that the turning point is $6.9 \mathrm{~m}$. The Mann-Whitney abrupt change test (Table S4) between the two groundwater depth intervals $(<6.9 \mathrm{~m}$ and $>6.9 \mathrm{~m})$, shows that the mean value for tree-ring width index significantly declines from 0.038 to 0.017 , (test statistic $Z_{c}=-6.12$ ). Based on the results above, we can conclude that the minimum groundwater depth for mature trees (DBHs $30-40 \mathrm{~cm}$ ) is $6.9 \mathrm{~m}$ and the most suitable groundwater depth should be $<6.9 \mathrm{~m}$.

The effect of groundwater depth on $P$. euphratica over-mature trees (DBHs $>40 \mathrm{~cm}$ ). In the lower reaches of the Tarim River, $P$. euphratica over-mature trees are mainly found in areas that are more than $1 \mathrm{~km}$ from the river. At this distance, the recharge ability of the river is weak and the groundwater table is low. However, the over-mature trees can resist sandstorms and protect the stability of the natural vegetation ecosystem on both sides of the river. Therefore, we analyzed the correlation between the growth of over-mature trees and groundwater depth (Fig. 4(5A,5B) and Table S5).

Figure $4(5 \mathrm{~A})$ shows that there is a significant negative correlation between tree-ring width index for over-mature trees and groundwater depth $\left(R^{2}=0.44, P<0.0001\right)$. The Mann-Kendall monotony trend test results (Table S5) show that an increase in groundwater depth leads to a significant decrease in tree-ring width index $\left(\left|Z_{c}\right|=10.24>\left|Z_{0.01}\right|=2.58\right)$. Therefore there is a considerable correlation between the two results. Figure $4(5 \mathrm{~B})$ shows that the turning point is $7.8 \mathrm{~m}$ for the tree-ring width index. The Mann-Whitney abrupt change test results (Table S5) for the two groundwater depth intervals $(<7.8 \mathrm{~m}$ and $>7.8 \mathrm{~m}$ ) show that the mean value for the tree-ring width index significantly drops (test statistic $(\mathrm{Zc})$ is -6.02 ) from 0.015 to 0.007 . Thus we can conclude that the minimum groundwater depth for over-mature trees (DBHs $>40 \mathrm{~cm}$ ) is $7.8 \mathrm{~m}$.

\section{Discussion}

The regeneration process for $\boldsymbol{P}$. euphratica seedlings. The intermediate disturbance hypothe$\operatorname{sis}^{56,57}$ is one of the most significant theories in ecology. This theory can be used to guide ecological protection and natural resource planning, and improve the regeneration of $P$. euphratica forest because river flooding disturbance can activate the soil seed bank and accelerate the regeneration of vegetation ${ }^{24}$.

$P$. euphratica seeds are smaller than most shrub seeds, and the radicles and plumules after germination are weaker than those of perennial herbs, so they do not compete well for water and have a low water storage capacity. Our results suggest that we should flood the area 2-3 times per year during the seed germination to seedling growth. However, over-frequent flooding is harmful for $P$. euphratica seedling establishment, and causes the $I V$ value to decline significantly when the frequency of flooding is $4-5$ times per year.

Based on the ecological water conveyance data, a minimum flow velocity of $20 \mathrm{~m}^{3} / \mathrm{s}$ can maintain the hydrological process in the lower reaches of the Tarim River, but an intensity below $20 \mathrm{~m}^{3} / \mathrm{s}$ does not lead to overflow. However, when the flow velocity is above $35 \mathrm{~m}^{3} / \mathrm{s}$, the scouring effect of the overflow on the river bed becomes severe and P. euphratica seedlings are barely able to establish and survive.

Our field research results showed that water-loving plants (such as Phragmites australis and Apluda mutica Linn.) are prevalent in areas where the flooding duration is over 30 days. However, we do not consider that the flora in the lower reaches of the Tarim River represents a climax community, as the ecosystem is constrained by poor water conditions. In contrast, P. euphratica is an important climax species in desert riparian forest, and can be adapted to the arid environment in the Tarim River Basin ${ }^{58}$. 


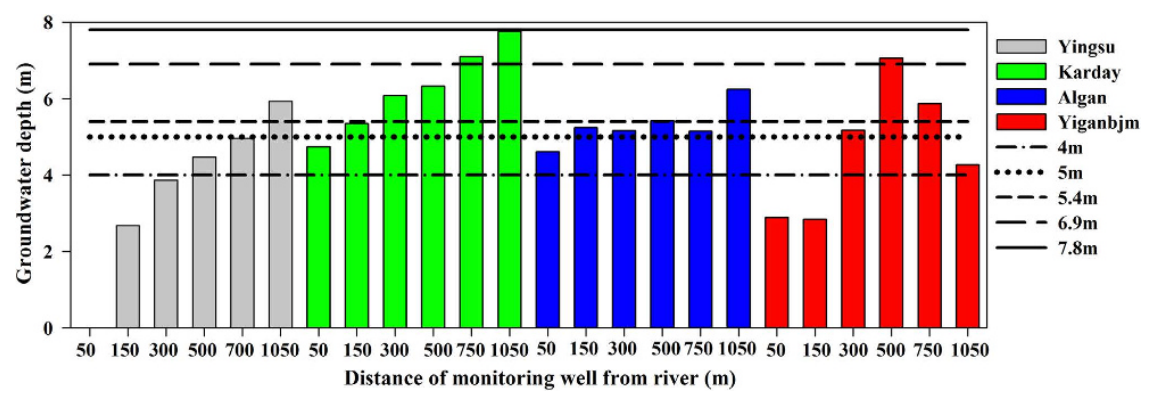

Figure 5. Groundwater depths at different distances from the river and the minimum groundwater depth requirements for $P$. euphratica trees.

In addition, some studies ${ }^{24,59,60}$ have shown that long term surface water will raise the groundwater depth and lead to salt accumulation in the surface soil. P. euphratica seedling growth requires a low salt environment, and if the salinity of the soil is high, seedling growth will be suppressed ${ }^{61}$. Therefore, the $I V$ value declines significantly when the surface water duration is over 20 days. Our quantitative results show that the most suitable flood duration is 15-20 days, which is more practicable and achievable when attempting to regenerate $P$. euphratica forest in downstream areas of the Tarim River.

Minimum groundwater depth for desert riparian $P$. euphratica forest. The growth of $P$. euphratica is close correlated with groundwater depth ${ }^{24}$. As the groundwater depth increases, survival and growth rates of P. euphratica decline and the trees become less sensitive to groundwater depth. Previous research ${ }^{8,62}$ showed that when the groundwater depth was $>4.5 \mathrm{~m}$, the significance of groundwater to $P$. euphratica growth becomes less important; the net photosynthetic rate and transpiration rate change, the proline and abscisic acid (ABA) contents become abnormal and the growth of P. euphratica is restricted. When the groundwater depth is $>8 \mathrm{~m}$, the trees begin to seriously decay or even die. According to previous study ${ }^{39}$, the correlation between radial stem growth and groundwater depth shows that the minimum groundwater interval is between $4.71 \mathrm{~m}$ and $8.62 \mathrm{~m}$. In reality, our results suggested that the most suitable groundwater depth is $<4 \mathrm{~m}$. The results of this study also indicate that the minimum groundwater range is between $4.0 \mathrm{~m}$ and $7.8 \mathrm{~m}$ ( i.e., young trees, $4.0 \mathrm{~m}$; near-mature trees, $5.0-5.4 \mathrm{~m}$; mature trees, $6.9 \mathrm{~m}$; over-mature trees, $7-8 \mathrm{~m}$ ), which is similar to previous research results. However, the most significant result in our study is that the minimum groundwater depths are confirmed for P. euphratica with different DBHs. In the future, the ecological water conveyance, through the use of the EWCE and the ecological water amount, can be defined according to the distribution features of $P$. euphratica forest and groundwater depth, Water is first transported to $P$. euphratica forest via deep groundwater. Therefore, this study will provide a theoretical basis and scientific guidance for the rational utilization of water resources and regeneration of $P$. euphratica forest in arid areas.

Our results show that the decrease in tree-ring width index becomes less sensitive to tree-ring growth as groundwater depth increases. The reason is that when P. euphratica is suffering from water stress, the tree reduces transpiration by secreting $\mathrm{ABA}$ to regulate stomatal conductance, which inhibits tree growth $^{62}$.

The best ecological water conveyance levels for $P$. euphratica protection in the lower reaches of the Tarim River. Based on the best flooding disturbance model (three times a year, duration 20 days and intensity $30 \mathrm{~m}^{3} / \mathrm{s}$ ), the calculated ecological water amount needed is 160 million $\mathrm{m}^{3}$. The data for ecological water conveyance between 2000 and 2012 in the lower reaches of the Tarim River showed that the annual average water volume was 320 million $\mathrm{m}^{3}$. Therefore, it can meet the water requirements of the flooding disturbance model for P. euphratica seedlings.

Our results also show that the groundwater depth should be shallower than the minimum groundwater depth (young trees, $4.0 \mathrm{~m}$; near-mature trees, $5.0-5.4 \mathrm{~m}$, mature trees, $6.9 \mathrm{~m}$ and over-mature trees, $7.8 \mathrm{~m}$ ) to ensure that $P$. euphratica trees grow well. Figure 5 shows that the groundwater depth in the four transects (Yingsu, Karday, Algan and Yiganbjm) have a strong relationship with the minimum groundwater depth for P. euphratica with different DBHs. The recorded data from the four transects shows that young trees (DBHs $4-10 \mathrm{~cm}$ ) are mainly found within $50 \mathrm{~m}$ of the channel and the majority is located in Algan. The near-mature trees (DBHs $10-30 \mathrm{~cm}$ ) are mainly found $150 \mathrm{~m}$ from the channel and mature trees $($ DBHs $30-40 \mathrm{~cm}$ ) and over-mature trees $(\mathrm{DBHs}>40 \mathrm{~cm})$ are mainly located $500 \mathrm{~m}$ and $1000 \mathrm{~m}$ away from the channel. Figure 5 also shows that the actual groundwater depths are higher than the minimum groundwater depth. According to a previous study result ${ }^{63}$, the ecological water requirement for maintaining P. euphratica forest transpiration and minimum groundwater depths is 311 million $\mathrm{m}^{3}$. In view of water shortages in this river basin ${ }^{18,37}$, and the requirements of ecological water and river 
flooding in the lower reaches, the most suitable range of ecological water conveyance is 311-320 million $\mathrm{m}^{3}$, which should be sufficient to regenerate and protect $P$. euphratica in the lower reaches of the Tarim River.

\section{Conclusion \\ Our results show that.}

(1) During the seed to young tree growth period, the most suitable flooding disturbance model for P. euphratica regeneration is 2-3 times per year with a duration of 15-20 days and an intensity of $25-30 \mathrm{~m}^{3} / \mathrm{s}$.

(2) The tree-ring width index for P. euphratica significantly declines as the groundwater depth increases.

(3) The minimum groundwater depths needed for $P$. euphratica young trees, near-mature trees, mature trees and over-mature trees are $4.0 \mathrm{~m}, 5.0-5.4 \mathrm{~m}, 6.9 \mathrm{~m}$ and $7.8 \mathrm{~m}$, respectively. In order to protect the desert riparian forest, the actual groundwater depth should be smaller than the minimum groundwater depth for each tree growth stage.

(4) The most suitable range for water conveyance amount is $311-320$ million $\mathrm{m}^{3}$, and this meets the requirements for optimal flooding and ecological water for $P$. euphratica growth in the lower reaches of Tarim River.

\section{References}

1. Watanabe, S., Kojima, K., Ide, Y. \& Sasaki, S. Effects of saline and osmotic stress on proline and sugar accumulation in Populus euphratica in vitro. Plant Cell Tiss. Org. 63, 199-206 (2000).

2. Koskela, J. et al. Conservation of forest genetic resources with special reference to endemic and endangered forest species in East Asia. In Plant genetic resources network in East Asia. Proceedings of the meeting for the regional network for conservation and use of plant genetic resources in East Asia, Ulaanbaatar, Mongolia, 13-16 August, 2001. International Plant Genetic Resources Institute (IPGRI) 6, 108-123 (2002).

3. Calagari, M. O. H. S. E. N., Modirrahmati, A. R. \& Asadi, F. A. R. H. A. D. Morphological variation in leaf traits of Populus euphratica Oliv. natural populations. Int. J. Agric. Biol. 8, 754-758 (2006).

4. Yang, Y. et al. Properties of plasma membrane H+-ATPase in salt-treated Populus euphratica callus. Plant Cell Rep. 26, 229-235 (2007).

5. Hao, X. et al. Hydraulic lift in Populus euphratica Oliv. from the desert riparian vegetation of the Tarim River Basin. J. Arid Environ. 74, 905-911 (2010).

6. Hou, L. G. et al. Evapotranspiration and crop coefficient of Populus euphratica Oliv forest during the growing season in the extreme arid region northwest China. Agr. Water Manage. 97, 351-356. (2010)

7. Food and Agriculture Organization of the United Nations and the Canadian Forest Service. Report of the International Boreal Forest Genetic Resources Workshop. 3-21 (1995) Available at:http://www.cfs.nrcan.gc.ca/pubwarehouse/pdfs/10268_e.pdf. (Accessed: 22th June 1995).

8. Chen, Y., Chen, Y., Li, W. \& Zhang, H. Response of the accumulation of proline in the bodies of Populus euphratica to the change of groundwater level at the lower reaches of Tarim River. Chinses Sci. Bull. 48, 1995-1999 (2003).

9. Meher-Homji, V. M. A. Phytoclimatic Approach to the Problem of Mediterraneity in the Indo-Pakistan Sub-Continent. Feddes Repertorium 83, 757-788 (1973).

10. Zhou, H. H., Chen, Y. N., Li, W. H. \& Chen, Y. P. Photosynthesis of Populus euphratica in relation to groundwater depths and high temperature in arid environment, northwest China. Photosynthetica 48, 257-268 (2010).

11. Wang S. J. The Status, Conservation and Recovery of Global Resources of Populus euphradica. World Forestry Research 6(5), 37-44 (1996). (In Chinese).

12. Osakabe, Y., Kajita, S. \& Osakabe, K. Genetic engineering of woody plants: current and future targets in a stressful environment. Physiol Plantarum 142, 105-117 (2011).

13. Xu, F., Feng, S., Wu, R. \& Du, F. K. Two highly validated SSR multiplexes (8-plex) for Euphrates' poplar, Populus euphratica (Salicaceae). Mol. Ecol. Resour. 13, 144-153 (2013).

14. Zhang, Y. M., Chen, Y. N. \& Pan, B. R. Distribution and floristics of desert plant communities in the lower reaches of Tarim River, southern Xinjiang, People's Republic of China. J. Arid Environ. 63, 772-784 (2005).

15. Cao, D. et al. Reproductive characteristics of a Populus euphratica population and prospects for its restoration in China. Plos One 7, e39121 (2012).

16. Xu, H., Zhou, B. \& Song, Y. Impacts of climate change on headstream runoff in the Tarim River Basin. Hydrol. Res. 42, 20-29 (2010).

17. Liu, Y. \& Chen, Y. Impact of population growth and land-use change on water resources and ecosystems of the arid Tarim River Basin in western China. Int. J. Sust. Dev. World 13, 295-305 (2006).

18. Hao, X., Chen, Y., Xu, C. \& Li, W. Impacts of climate change and human activities on the surface runoff in the Tarim River Basin over the last fifty years. Water Resour. Manag. 22, 1159-1171 (2008).

19. Xu, H., Ye, M., Song, Y. \& Chen, Y. The natural vegetation responses to the groundwater change resulting from ecological water conveyances to the lower Tarim River. Environ. Monit. Assess. 131, 37-48 (2007).

20. Liu, D. et al. Ecohydrological evolution model on riparian vegetation in hyperarid regions and its validation in the lower reach of Tarim River. Hydrol. Process. 26, 2049-2060 (2012).

21. Zhao, Z., Wang, R., Sun, H. \& Zhang, H. Assessment of water-recharging based on ecological features of riparian forest in the lower reaches of Tarim River. Chinese Sci. Bull. 51, 37-42 (2006).

22. Westermann, J., Zerbe, S. \& Eckstein, D. Age Structure and Growth of Degraded Populus euphratica Floodplain Forests in Northwest China and Perspectives for Their Recovery. J. Integr. Plant Biol. 50, 536-546 (2008).

23. Wiehle, M., Eusemann, P., Thevs, N. \& Schnittler, M. Root suckering patterns in Populus euphratica (Euphrates poplar, Salicaceae). Trees 23, 991-1001 (2009).

24. Xu H, Ye M. \& Li J. The ecological characteristics of the riparian vegetation affected by river overflowing disturbance in the lower Tarim River. Environ. Geol. 58, 1749-1755 (2009).

25. Aishan, T. et al. Eco-morphological response of floodplain forests (Populus euphratica Oliv.) to water diversion in the lower Tarim River, northwest China. Environ. Earth Sci. 73, 533-545 (2015). 
26. Sher, A. A., Marshall, D. L. \& Gilbert, S. A. Competition between native Populus deltoides and invasive Tamarix ramosissima and the implications for reestablishing flooding disturbance. Conserv. Biol. 14, 1744-1754 (2000).

27. Nilsson, C. \& Svedmark, M. Basic principles and ecological consequences of changing water regimes: riparian plant communities. Environ. Manage. 30, 468-480 (2002).

28. Capon, S. J. \& Brock, M. A. Flooding, soil seed bank dynamics and vegetation resilience of a hydrologically variable desert floodplain. Freshwater Biol. 51, 206-223 (2006).

29. Quesada, C. A. et al. Regional and large-scale patterns in Amazon forest structure and function are mediated by variations in soil physical and chemical properties. Biogeosciences Discussion 6, 3993-4057 (2009).

30. Ward, J. V., Tockner, K., Uehlinger, U. \& Malard, F. Understanding natural patterns and processes in river corridors as the basis for effective river restoration. Regul. River. 17, 311-323 (2001).

31. Vervuren, P. J. A., Blom, C. W. P. M. \& De Kroon, H. Extreme flooding events on the Rhine and the survival and distribution of riparian plant species. J. Ecol. 91, 135-146 (2003).

32. Palmer, M. A. et al. Standards for ecologically successful river restoration. J. Appl. Ecol. 42, 208-217 (2005).

33. Stockton, C. W. \& Jacoby, G. C. Long-term surface-water supply and streamflow trends in the upper Colorado River Basin based on tree-ring analyses. Los Angeles: Institute of Geophysics and Planetary Physics, University of California, 38-43 (1976).

34. Cleaveland, M. K. \& Stahle, D. W. Tree ring analysis of surplus and deficit runoff in the White River, Arkansas. Water Resour. Res. 25, 1391-1401 (1989).

35. Shah, S. K., Bhattacharyya, A. \& Chaudhary, V. Streamflow reconstruction of Eastern Himalaya River, Lachen 'Chhu', North Sikkim, based on tree-ring data of Larix griffithiana from Zemu Glacier basin. Dendrochronologia 32, 97-106 (2014).

36. Liu, Y. et al. Tree-ring hydrologic reconstructions for the Heihe River watershed, western China since AD 1430. Water Res. 44, 2781-2792 (2010).

37. Ling, H. B. et al. Configuration ofwaterresources for a typical river basin in an aridregion of China based on the ecological water requirements (EWRs) of desert riparian vegetation. Global Planet. Change 122, 292-304 (2014).

38. Chen, Y. N. et al. Ground-water level affects plant species diversity along the lower reaches of the Tarim river, Western China. J. Arid Environ. 66, 231-246 (2006).

39. Deng, X. Y. et al. Impact of long-term zero-flow and ecological water conveyance on the radial increment of Populus euphratica in the lower reaches of the Tarim River, Xinjiang, China. Reg. Environ. Change 15, 13-23 (2015).

40. Chen, Y. N. et al. Rational groundwater table indicated by the eco-physiological parameters of the vegetation: a case study of ecological restoration in the lower reaches of the Tarim River. Chinese Sci. Bull. 51, 8-15 (2006).

41. Yu, P. J. et al. Effects of ecological water conveyance on the ring increments of Populus euphratica in the lower reaches of Tarim River. J. Forest. Res-Jpn. 17, 413-420 (2012).

42. Huang, T. \& Pang, Z. Changes in groundwater induced by water diversion in the Lower Tarim River, Xinjiang Uygur, NW China: Evidence from environmental isotopes and water chemistry. J. Hydrol. 387, 188-201 (2010).

43. Dyksterhuis E J. Condition and management of range land based on quantitative ecology. J. RANGE. MANAGE. 2, 104-115 (1949).

44. Curtis, J. T. \& Mcintosh, R. P. An upland forest continuum in the prairie-forest border region of Wisconsin. Ecology 32, 476-496 (1951).

45. Fritts, H. C. in Tree rings and climate (ed Jovanovich, W.) 1-412 (Academic Press, 1976).

46. Black, B. A., Gillespie, D. C., Maclellan, S. E. \& Hand, C. M. Establishing highly accurate production-age data using the tree-ring technique of crossdating: a case study for Pacific geoduck (Panopea abrupta). Can. J. Fish. Aquat. Sci. 65, 2572-2578 (2018).

47. Holmes, R. L. Computer-assisted quality control in tree-ring dating and measurement. Tree-Ring Bull 43, 49-78 (1983).

48. Heinrich, I. et al. Interdecadal modulation of the relationship between ENSO, IPO, and precipitation: insights from tree rings in Australia. Clim. Dynam. 33, 63-73 (2009).

49. Cook, E. R. \& Peters, K. Calculating unbiased tree-ring indices for the study of climatic and environmental change. Holocene 7 , 361-370 (1997).

50. Safari, B. Trend analysis of the mean annual temperature in Rwanda during the last fifty two years. J. Environ. Prot. ECOL. 3, 538-551 (2012).

51. Zimmerman, D. W. Comparative power of Student $t$ test and Mann-Whitney $\mathrm{U}$ test for unequal sample sizes and variances. The Journal of Experimental Education 55, 171-174 (1987).

52. Pascual-Hortal, L. \& Saura, S. Comparison and development of new graph-based landscape connectivity indices: towards the priorization of habitat patches and corridors for conservation. Landscape. Ecol. 21, 959-967 (2006).

53. Rüger, N., Schlüter, M. \& Matthies, M. A fuzzy habitat suitability index for Populus euphratica in the Northern Amudarya delta (Uzbekistan). Ecol. Model. 184, 313-328 (2005).

54. Eusemann, P., Petzold, A., Thevs, N. \& Schnittler, M. Growth patterns and genetic structure of Populus euphratica Oliv.(Salicaceae) forests in NW China-Implications for conservation and management. Forest Ecol. Manag. 297, 27-36 (2013).

55. Zhu, Y. et al. Simulation of Populus euphratica root uptake of groundwater in an arid woodland of the Ejina Basin, China. Hydrol. Process. 23, 2460-2469 (2009).

56. Connell, J. H. Diversity in tropical rain forests and coral reefs. Science 199, 1302-1310 (1978).

57. Roxburgh, S. H., Shea, K. \& Wilson, J. B. The intermediate disturbance hypothesis: patch dynamics and mechanisms of species coexistence. Ecology 85, 359-371 (2004).

58. Wang, Z. et al. Effects of water treatments on the activation of soil seed banks-A case study on the lower reaches of the Tarim River. Prog. Nat. Sci. 19, 733-740 (2009).

59. Jolly, I. D., Walker, G. R. \& Thorburn, P. J. Salt accumulation in semi-arid floodplain soils with implications for forest health. J. Hydrol. 150, 589-614 (1993).

60. Morris, J. D. \& Collopy, J. J. Water use and salt accumulation by Eucalyptus camaldulensis and Casuarina cunninghamiana on a site with shallow saline groundwater. Agr. Water Manage. 39, 205-227 (1999).

61. Chen, S. et al. Salt, nutrient uptake and transport, and ABA of Populus euphratica; a hybrid in response to increasing soil $\mathrm{NaCl}$. Trees 15, 186-194 (2001).

62. Fu, A. H. et al. Analysis on the Changes of Stems Water Potential of Populus Euphratica in Different Groundwater Level in Lower Reaches of Tarim River in Xinjiang. Arid Land Geography 27, 207-211 (2004). (In Chinese)

63. Liu, X.H. et al. Ecological Water Requirements in the Lower Reaches of the Tarim River. Journal of Desert Research 33, 1198-1205. (In Chinese)

\section{Acknowledgments}

This work was supported by the National Natural Science Foundation of China $(41471099,41171427$, 31370551 and 31400466 ), West Light Foundation of The Chinese Academy of Sciences (XBBS-2014-13) and the Independent Subject of State Key Laboratory of Desert and Oasis Ecology. 


\section{Author Contributions}

H.L. and H.X. wrote the main manuscript text and prepared Figures 1-5. P.Z. advised the study design, data analyses, and revised the paper. X.Z. performed the experiments and collected the data. All authors had reviewed and agreed on the contents of the paper.

\section{Additional Information}

Supplementary information accompanies this paper at http://www.nature.com/srep

Competing financial interests: The authors declare no competing financial interests.

How to cite this article: Ling, H. et al. How to Regenerate and Protect Desert Riparian Populus euphratica Forest in Arid Areas. Sci. Rep. 5, 15418; doi: 10.1038/srep15418 (2015).

(c) (i) This work is licensed under a Creative Commons Attribution 4.0 International License. The images or other third party material in this article are included in the article's Creative Commons license, unless indicated otherwise in the credit line; if the material is not included under the Creative Commons license, users will need to obtain permission from the license holder to reproduce the material. To view a copy of this license, visit http://creativecommons.org/licenses/by/4.0/ 